CuPAUAM. 20, 1993, pp. 185-194

\title{
NUEVAS APORTACIONES AL ESTUDIO DE UNAS MONEDAS DE TALLER INCIERTO
}

\author{
Alicia Arévalo GonZÁlez \\ Dpto. Prehistoria y Arqueología \\ Universidad Autónoma de Madrid.
}

\section{Resumen}

Este artículo aporta nuevos datos arqueológicos y numismáticos para el análisis de unas monedas, cuyo lugar de emisión desconocemos al carecer de leyenda toponímica, pero que pueden ser adscritas al territorio controlado por la ciudad de Obulco.

Por último, presentamos dos epígrafes que pueden servir para encuadrar a los antiguos habitantes de las circunscripciones rurales en el seno de la sociedad municipal de Obulco.

\section{Summary}

This article shows new archeological and numismatic data for the analysis of some coins, whose place of issue is unknown because of lack of a toponomic legend, but which can be assigned to the territory controlled by the city of Obulco.

Finally, we present two inscriptions which serve as a link to situate the ancient inhabitants of the rural divisions in the center of the municipal society of Obulco.

Es un placer volver sobre estudios publicados con anterioridad a los cuales se puede aportar una nueva información, que viene apoyar lo dicho en aquella ocasión.

En nuestro artículo sobre unas monedas hispánicas de taller incierto (Arévalo González, 1990, 710), clasificadas asi por Vives y Escudero (1926, 64, n. ${ }^{0} 1$ y 2 ; lám. XCIX-1 y 2) por no presentar el topónimo del taller, consideramos que subsistían motivos suficientes para aceptar que estas monedas imitaban a las acuñaciones de Obulco, en el supuesto de que se trataran de monedas emitidas por un taller desconocido. Hipótesis que tenía a su favor el que no consta en sus leyendas el topónimo, pero no excluíamos la posibilidad de que fueran emitidas por la propio Obulco o bajo su amparo. 
Los metivos que nos llevaron hacer tales consideraciones fueron de indole tipológico, epigráfico y metrológico, debido a la semejanza con las acuñaciones obulconenses, y en especial con la serie IV (Arévalo González, 1993).

Las novedades que presentamos en este artículo son: primero,dar a conocer nuevos ejemplares $y$, segundo, hacer nuevas consideraciones sobre las posibles causas que llevaron a la acuñación de estas singulares piezas.

En la actualidad conocemos catorce ejemplares (vid. Catálogo), de ellos: los dos pertenecientes al Museo Arqueológico Nacional fueron publicados en primer lugar por Vives y Escudero (1926, lám. XCIX-1 y 2), posteriormente por Navascués (1971, 31, n. ${ }^{\circ} 1010$ y 1011, lám. XXXV) y, por nosotros mismos (Arévalo Gonzalez, 1990, n. 1 y 3); el perteneciente a la colección Guadán fue publicado por él mismo (1980, 70, n. ${ }^{\circ} 237$ ); los depositados en el Gabinete Numismático de Cataluña, en el Museo de Granada y uno de una colección particular fueron igualmente dados a conocer por nosotros (Arévalo González, 1990, n. ${ }^{\circ}$ 2, 4 y 5); el resto de las piezas, que ahora presentamos, son inéditas.

Estas monedas, como indicabamos antes, son semejantes a la serie IV de Obulco; al igual que ella llevan como tipo de anverso una cabeza femenina a derecha, con el característico peinado de mońo y trenza que rodea la cabeza; en el reverso, arado y espiga a izquierda, entre ellos leyenda en escri-

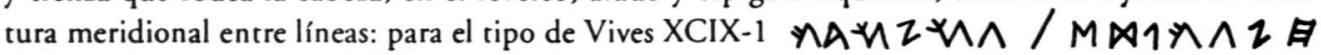

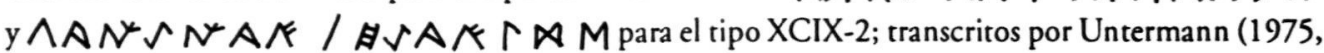
341, A.102) como Kankinai / G22b-kiailkos y Kaankinai / G22b-kiailkos, respectivamente. Sin embargo, tanto el cuño de anverso como de reverso son distintos a cualquiera de los que conocemos de la serie IV de Obulco. El de anverso, aunque presenta la típica cabeza femenina, el estilo es diferente y no cabe duda de que se trata de una matriz distinta. El cuño de reverso es evidente que también es diferente pues presenta dos nombre de magistrados monetales no recogidos en las acuñaciones obulconenses.

Existen además elementos suficientes para considerar que para la acuñación de estas monedas se utilizaron dos cuños de reverso diferentes: el primero presenta el arado y la espiga orientados hacia la izquierda y la leyenda en sentido retrógrado; mientras que el segundo tiene el arado y la espiga hacia la derecha y la leyenda en sentido directo. Por lo que se refiere a los anversos no parece que se utilizaran más de un cuño para su confección. Esto es lo que nos ha llevado a formar, con estos catorce ejemplares, dos grandes grupos-cuños.

Los pesos de estas monedas oscilan entre los 18,50 y 12,70 grs., que coinciden también con la serie de magistrados en caracteres meridionales de Obulco, datada entre el 165 a.C. y el 110 a.C. a tenor de la información facilitada por los hallazgos monetales y las reacuñaciones, por lo que estas monedas inciertas pueden ser adjudicadas a la segunda mitad del siglo II a.C.

Hechas estas matizaciones y al no contar con datos sobre la procedencia de estas piezas, salvo para el ejemplar n. ${ }^{\circ} 14$, pero que al ser de un hallazgo superficial en Pinos Puente (Granada), tampoco aporta datos clarificadores sobre la adscripción de estas acuñaciones a un taller determinado, queremos hacer ciertas consideraciones histórico-arqueológicas sobre la posibilidad de que sean emitidas por la propia Obulco o bajo su amparo.

Los datos recogidos en la campiña de Porcuna (Jaén) ponen en evidencia que en el territorio controlado por Obulco se dió una explotación agrícola de gran envergadura. Tal explotación tenía sentadas las bases desde tiempos remotos, pues la existencia desde el Neolítico Final de una tecnología lítica espe- 

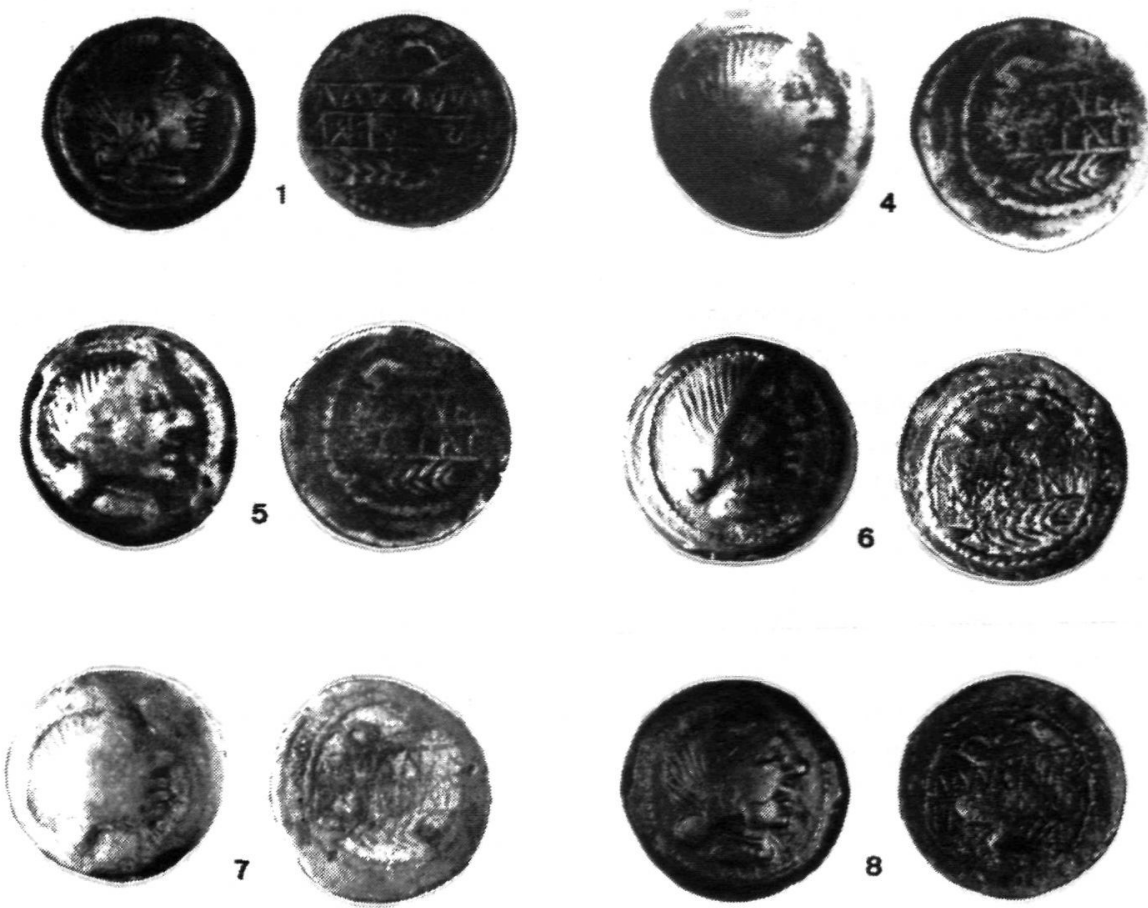

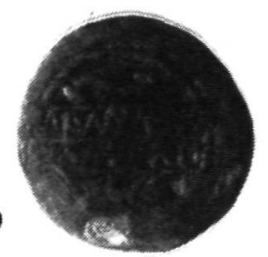

Lamina

cializada en las actividades agrícolas y su mantenimiento de forma prioritaria en todo el desarrollo del Cobre y del Bronce (Arteaga, 1987, 279-288; Arteaga, Nocete, Ramos, Recuerda y Roos, 1988, 395400 ), es un elemento fundamental para poder explicar el proceso histórico que desencadenó la acumulación de excedentes y toda una serie de cambios económicos y políticos que conducirían hacia for- 
maciones económicas jerarquizadas, hasta llegar a convertir a la ciudad túrdula de Ipolka, en el período ibérico pleno, en el punto de atracción e interés económico de la Campiña, según se deduce de las fuentes y confirma la arqueología (Arteaga, 1987, 284-286). Por ella pasa, como nos informa Estrabón (Geogr., III, 4, 9) la antigua vía de los íberos, ruta que daba salida a las riquezas mineras de Sierra Morena y a las cerealistas de la Campiña, lo que nos remite al papel comercial que este centro impone a las poblaciones de la vega del Guadalquivir, al hacer pasar los circuitos de distribución del producto por un punto.

La capitalidad comercial y económica de Ipolka será mantenida, en época romana, por la ciudad de Obulco, a la luz de los datos que proporciona el entorno urbano y el territorio circundante (Arteaga, Ramos, Nocete, Roos y Burgos, 1990, 238-243; Arteaga, Ramos, Nocete, Roos y Lizcano, en prensa). En las cercanías del nucleo urbano de Obulco, en la zona de San Marcos, se ha localizado una enorme cantidad de silos, que tienen hasta seis metros de profundidad y cinco metros de anchura máxima, rellenos de material ibero-romano. La capacidad de almacenaje que muestran estos silos ilustra por sí misma la existencia de una sorprendente capacidad productiva que no podía haberse desarrollado en las cercanías de la ciudad, sino en unas mayores extensiones del territorio campiñense y denotan la existencia de una centralización de la producción.

Esta centralización se llevó a cabo bajo las directrices del centro nuclear de la ciudad de Obulco y el control de las tierras fértiles, apropiadas para las explotaciones agro-pecuarias, y de las tierras de secano, aptas para el desarrollo de actividades cerealísticas, fue ejercido por las torres vigías, los recintos fortificados y las plazas fuertes situados en los alrededores. De esta forma Obulco controlaba un territorio que como señalan Arteaga, Ramos, Nocete, Roos y Lizcano (en prensa) se hallaba adscrito a su estructura estatal y cuyas fronteras más extremas parece que estaban en los alrededores de los ríos Guadalbullón y Guadajoz.

Por lo que la posible explicación para la emisión de estas singulares piezas quizá la tengamos en la propia organización socio-política de esta ciudad. Es decir, estas monedas pudieron haber sido acuñadas dentro del territorio controlado por Obulco pero fuera del centro urbano, no haciendo falta que esta ciudad amparara con su nombre estas acuñaciones, pues hicieron constar los nombres de quienes tuvieron la responsabilidad delegada de controlar estas acuñaciones.

Es un hecho que en la antigüedad existieron emisiones con una finalidad específica, un gran número de acuñaciones romanas fueron emitidas para las tropas, y aunque no conste en sus leyendas se han podido aislar del resto porque su circulación en determinadas áreas geográficas coinciden con los movimientos de tropa en esas fechas y zonas; estas acuñaciones han sido estudiadas por M. H. Crawford (1974, 604), que recoge las emisiones de época republicana, y M. P. García-Bellido (1985, 65-72 y 1990 , 129-136), que ha identificado victoriatos romanos acuñados en Hispania, en estrecha relación con las tropas de Escipión en España durante la II Guerra Púnica. De igual forma, en las áreas mineras se necesitaba un numerario que sufragase los gastos salariales de estas explotaciones, así M. P. García-Bellido (1982), en su estudio sobre las monedas de Cástulo, pudo aislar las emisiones mineras del resto del conjunto castulonense y, con posterioridad, la misma autora $(1986,13-46)$ ha ido recogiendo las acuñaciones con tipología minera en Hispania republicana que han ido saliendo a la luz y las emisiones mineras con tipos no alusivos pero que pueden ser adscritos a este ámbito por su circulación o por otros datos complementarios como factura, estilo, etc. Debió de existir este mismo fenómeno para otras necesidades 
económicas, puesto que como aclara M. P. García-Bellido (1986, 24) "sabemos que Roma no acuña de forma regular hasta mediados del siglo I d.C. y antes el Estado acuñaba sólo movido por necesidades concretas".

Al estudiar las monedas de Obulco (Arévalo González, 1993) constatamos que desde el momento de la temprana presencia romana en esta ciudad se debieron extender las formas y elementos económicos típicos del mundo romano, al lado de éstos coexistieron los propios del pueblo indígena allí asentado. No fue una coexistencia estática, sino que se produjo una influencia, representada especialmente por las transformaciones que los elementos económicos de la organización social indígena sufrieron a consecuencia de la expansión de los elementos romanos. Uno de estos elementos fue la incorporación a la economía monetal, que produjo una nueva realidad social, la existencia del trabajador agrícola asalariado.

Este trabajador podría realizar desde trabajos de carácter temporal, como la siembra y la recolección, faenas agrícolas con una necesidad de mano de obra que no podemos pensar que fuera exclusivamente esclava, pues como señala Garnsey $(1978,145)$ el tiempo que transcurre entre estas faenas llega ser tan largo que resulta costoso su manutención. Así lo reconoce el propio Columela (III, 3): es más productivo el trabajo libre que el servil, pues además del precio incial de compra, está la manutención. Es decir, para las labores estacionales se requerirían temporeros, gentes a las que el Estado podría obligar, bajo pago de un salario, a trabajar (Corbier, 1980, vol. 2, 73-79).

Por ello consideramnos que la moneda de Obulco fue creada para el ámbito agrícola, su tipología y circulación monetaria lo corroboraban, por lo que al igual que en las grandes explotaciones mineras, las organizaciones agrarias necesitaban y dependí an de una economía monetal. Esta dependencia se ve reforzada por la existencia de piezas en plomo con tipología agraria (Casariego, Cores y Pliego, 1987, 16; García-Bellido, 1986, 13-40; Gonzalbes Cravioto, 1987-89, 110-111), copia exacta de determinadas acuñaciones agrícolas, que indudablemente indican que cuando no existía el suficiente numerario, se emitía algo que lo supliese en sus funciones, como representantes de pequeñas fracciones de numerario oficial o bien como téseras que representaban de un modo u otro un valor de cambio.

Las hipótesis planteadas por nosotros sobre las acuñaciones de Obulco y las defendidas por GarcíaBellido (1986, 13-46), al estudiar una serie de documentos agrícolas - téseras, plomos y contramarcashan venido a demostrar que las exploraciones agrícolas de época republicana, se organizaron social y económicamente de forma similar a las mineras, por lo que se abren nuevas posibilidades en la interpretación de los instrumentos económicos monetales de tipología agraria que nos han llegado, y las monedas que ahora estudiamos son un claro ejemplo de ello; sin duda fueron concebidas para abastecer las necesidades de numerario de alguna circunscripción rural del territorio controlado por Obulco.

De la misma forma que en el ámbiro minero, donde debido a la lejanía de las minas de los importantes centros capitalizadores y responsables de la minería de cada zona y a la dificultad de acceso a las zonas donde residían los usuarios de las monedas, hizo que las ciudades, cabezas de los distritos mineros, ampararan con su nombre acuñaciones que no se hicieron dentro de su casco urbano, es decir legalizaron con su nombre unas emisiones que se acuñaban probablemente a pie de mina, como se demuestra en las acuñaciones mineras de Cástulo, las cuales como señala M. P. García-Bellido (1982, 147), "debieron recibir el permiso senatorial siempre que de alguna manera fuesen marcadas y diferenciadas, para que quienes 
tuviesen la responsabilidad delegada pudiesen controlar su acuñación"; de ahí que estas emisiones mineras aparezcan diferenciadas de las emisiones urbanas mediante la colocación del símbolo mano, o en los cuadrantes mineros de Bílbilis (García-Bellido, 1986, 17-19), ciudad responsable, junto a Turiaso, de la manufactura y comercialización del mineral procedente del Moncayo, que fueron acuñados in situ debido a la carencia de moneda pequeña en las minas.

Una cuestión más queremos abordar, los habitantes de estas antiguas circunscripciones rurales debieron quedar encuadrados en época imperial, en el seno de la sociedad municipal de Obulco; el hecho de que en las fuentes epigráficas de este municipio encontremos la fórmula municipes et incolae (CIL II, 2132), pone de manifiesto la existencia de un sector de la población diferenciado del cuerpo de ciudadanos y, nos planteamos si pudo ser ese grupo social el que habitaba en el ámbito rural. Existe aún otra inscripción (CIL II, 2135) donde un individuo hace constar su condición de incola; la importancia de ambos epígrafes merece que los reproduzcamos:

M(arco).VALERIO. M(arci).F(ilio).M(arci).N(epoti).

Q(vinti).PRO(nepoti).GAL(eria).PVLLINO

IIVIRO.LEG(ato).PERPETVO

MVNIC(ipii).PONTIF(icensis).

5 PRAEF(ecto).FABR(vm).FLAM(ini)

PONTIF(ici).AVG(vsti).MV

NICIPES.ET.INCOLAE

a P(vblivs).RVTILIVS.P(vblii).L(ibertvs).MENELAVO[S]

INCOLA.EX.D(ecreto).D(ecurionvm).MVNICIP(vm)

MVNICIPI(i).PONTIF(icensis).D(e).S(va).P(ecvnia)

No pretendemos hacer un exámen del concepto de incola, el tema sería prolijo y no es el objetivo de este trabajo estudiarlo con profundidad, pues existen además estudios monográficos sobre ello (Portillo Martín, 1983); lo que queremos mostrar es la posible conexión entre el sector de población que delimita el concepto de los incolae y la comunidad para la que fueron acuñadas las monedas analizadas. Si bien queremos asentar previamente una serie de precisiones que nos parecen necesarias con respecto al término incola.

Según las formulaciones jurídicas (Portillo, 1983, 33 ss.; Rodríguez Neila, 1978, 147 ss.) los incolae serían personas que habiendo nacido en un determinado lugar, por alguna circunstancia se encuentran fuera de su municipio o colonia y se hallan residiendo en otra ciudad. Sin embargo, como seńala Lomas Salmonte (1987-88, 383-395) el término y la realidad de los incolae no se agota en las formulaciones jurídicas sino que existe también una realidad social, que proporcionan las fuentes literarias y epigráficas. Así Livio $(28,3,1-3)$ al hacer referencia a los indígenas de Orongis, dedicados fundamentalmente al laboreo de las minas, los califica de incolae. Desde esta perspectiva los incolae serían los habitantes autóctonos de un lugar, que tras la ocupación y asentamiento romano del mismo, siguen habitándolo y dedicándose a los mismos trabajos que siempre habían realizado. 
En cuanto a la información epigráfica nos parece igualmente significativo el uso del término incola para el sector de la población que aparece ligada al ámbito rural, incolae ruris telluris (CIL IV, 4520). Además, Lomas Salmonte (1987-88, 387-388) alude, de forma especial, a una inscripción donde se menciona a los municipes e incolae de dos pagi, el Translucano y el Suburbano (CIL II, 1041), lo que le inclina a pensar "en los incolae como nativos en su lugar de residencia, su ruralidad; viviendo más allá del bosque unos, extramuros más próximos a la ciudad los otros. El ser, en definitiva, una población rural, como especifica el epigrafe, es para mí signo altamente elocuente, si bien es cierto que nos todos los rurales son incolae tampoco es cierta la recíproca; pero que la mayor densidad de incolae nos la ofrece el campo me parece innegable; de ahí que me permita afirmar que la ruralidad, y para zonas romanizadas y desde la perspectiva de Roma, es signo determinante de incola, aunque no único".

En las dos inscripciones que nosotros presentamos resulta difícil determinar si se trata del individuo domiciliado en otra ciudad distinta a la de su origen, o si es el indígena que sigue viviendo, en este caso, en los mismos campos que sus antepasados. Sin embargo, esta última realidad social encuadra perfectamente en el entramado económico y político de Obulco; así la población rural dedicada al laboreo de la tierra, que vivía más allá del nucleo urbano, cuya existencia tenemos constatada desde época republicana, por la información facilitada por las excavaciones arqueológicas realizadas en los alrededores de Porcuna (Jaén) y por las monedas acuñadas en el ámbito rural, que cubrían las necesidades más habituales de esa comunidad; con el proceso de municipalización a esta población rural se la dejó habitar en el territorio, pero con un estatuto jurídico inferior: el estatuto de incolae.

Lo interesante, si la interpretación resulta correcta, es que muy probablemente estos documentos numismáticos y epigráficos son los que más pueden ayudar a una mejor comprensión del sistema social agrícola, ya que tenemos ante nuestras manos el mismo objeto y la misma imagen que vieron sus usuarios, con la posibilidad de interpretarla como to hicieron sus dueños.

\section{CATALOGO}

\section{Aclaraciones al Catálogo}

El peso de los ejemplares se da en gramos, el módulo en milímetros y la posición de cuños mediante las horas del reloj. Los ejemplares que pertenecen a fondos de Museos incluyen el número de inventario.

\section{Abreviaturas}

$\begin{array}{ll}\text { Anv. } & \text { Anverso } \\ \text { C } & \text { Conservación. } \\ \text { Col. } & \text { Colección. } \\ \text { GNC } & \text { Gabinete Numismático de Cataluña. } \\ \text { Herrero } & \text { Herrero (Catálogo de subastas). }\end{array}$




$\begin{array}{ll}\text { IVDJ } & \text { Instituto Valencia de Don Juan. } \\ \text { Lám. } & \text { Lámina. } \\ \text { MAG } & \text { Museo Arqueológico de Granada. } \\ \text { MAN } & \text { Museo Arqueológico Nacional. } \\ \text { PC } & \text { Posición de cuños. } \\ \text { Ref. Bibl. } & \text { Referencias Bibliográficas. } \\ \text { Rev. } & \text { Reverso. } \\ \text { VP } & \text { Vico y Pliego (Catálogo de subastas). }\end{array}$

\section{Referencias Bibliográficas}

$\begin{array}{ll}\text { Arévalo } & \text { Arévalo González, A., } 1990 . \\ \text { Guadán } & \text { Guadán, A., 1980. } \\ \text { Nav. } & \text { Navascués, J.M., 1971. } \\ \text { RO.PP. } & \text { Rodríguez Oliva, P. y Peregrín Pardo, F., } 1980 . \\ \text { V. } & \text { Vives y Escudero, A., } 1926 .\end{array}$

\section{SERIE I}

\section{Ases}

\section{Grupo 1}

Anv.-Cabeza femenina a derecha, con el cabello recogido en una trenza que rodea la cabeza y se sujeta atrás en un moño, a la altura de la nuca. Adornada con collar de pequeños colgantes y pendíente. Anepígrafo. Gráfila de puntos.

Rev.-Arado y espiga tumbada, ambos a izquierda; entre ellos, leyenda externa, entre líneas

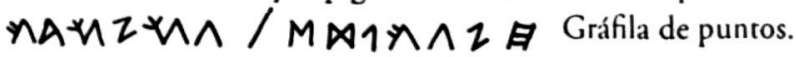

\begin{tabular}{cccrccrl}
\hline N. & Peso & Módulo & PC & C & Procedencia & Localización & \multicolumn{1}{c}{ Ref. Bibl. } \\
\hline 1 & 16,30 & 27,8 & 4 & R & & MAN 24498 & V. 1, lám. \\
& & & & & & & XCIX-1 \\
& & & & & & & Nav. 1010, \\
& & & & & & & lám. XXV \\
& & & & & & & Arévalo 1 \\
2 & 12,85 & & 10 & R & Col. Gómez Moreno & IVD & Inédita \\
3 & 18,50 & 27 & 8 & R & & Col. Guadán & Guadán 237
\end{tabular}




\section{Grupo 2}

Anv.-Cabeza femenina a derecha, con el cabello recogido en una trenza que rodea la cabeza y se sujeta atrás en un moño, a la altura de la nuca. Adornada con collar de pequeños colgantes y pendiente. Anepgrafo. Gráfila de puntos.

Rev.-Arado y espiga tumbada, ambos a derecha; entre ellos, leyenda externa, entre líneas $\triangle A N \backsim N A N /$ A

\begin{tabular}{|c|c|c|c|c|c|c|c|}
\hline N.o & Peso & Módulo & $\mathrm{PC}$ & $\mathrm{C}$ & Procedencia & Localización & Ref. Bibl. \\
\hline 4 & 17,45 & & 3 & $\mathrm{R}$ & & Col. Particular & Inédita \\
\hline 5 & 17,43 & & & $\mathrm{R}$ & & VP, 29, n.o 84 & Inédita \\
\hline 6 & 16,01 & 30,1 & 4 & $\mathrm{R}$ & & Col. Vila & Arévalo 5 \\
\hline 7 & 15,73 & 29,5 & 3 & M & & GNC 105879 & Arévalo 4 \\
\hline 8 & 14,45 & 28,9 & 4 & $\mathrm{R}$ & & MAN 24499 & $\begin{array}{l}\text { V. 2, lám. } \\
\text { XCIX-2. } \\
\text { Nav. } 1011 \text {, } \\
\text { lám. XXV. } \\
\text { Arévalo } 3\end{array}$ \\
\hline 9 & 13,5 & & 9 & $M$ & & Col. Particular & Inédita \\
\hline 10 & 13,18 & & 9 & $\mathrm{R}$ & Col. Gómez Moreno & IVDJ & Inédita \\
\hline 11 & 13,06 & & & $\mathrm{R}$ & & Herrero II-89, 115 & Inédita \\
\hline 12 & 13,00 & 28 & 2 & M & Col. Gómez Moreno & MAG 221 & Arévalo 2 \\
\hline 13 & 12,70 & & 6 & $\mathrm{R}$ & & IVDJ & Inédita \\
\hline 14 & & 26,8 & 9 & $\mathrm{R}$ & Pinos Puente (Granada) & & RO.PP 62 \\
\hline
\end{tabular}

\section{BIBLIOGRAFIA}

Arévalo GonzÁlez, A., 1990: "Consideraciones sobre unas monedas de taller incierto", Gaceta Numismática, 99, pp. 7-10.

- 1993: Las monedas de Obulco, Madrid, Universidad Autónoma de Madrid, Tesis Doctorales en microfichas.

ARTEAGA, O., 1987: "Excavaciones arqueológicas sistemáticas en el cerro de Los Alcores (Porcuna, Jaén). Informe preliminar sobre la campaña de 1985", Anuario Arqueológico de Andalucia, 1985, pp. 279-288.

ARTEaga, O.; Nocete, F.; Ra.mos, J.; Rf.Cuf.Rda, A., y Roos, A. M.a, 1988: "Excavaciones sistemáticas en el cerro de El Albalate (Porcuna, Jaén)", Anuario Arqueológico de Andalucia, 1986, pp. $395-400$. 
Arteaga, O.; Ramos, J.; Nocete, F.; RoOs, A., y Burgos, A., 1990: "La ciudad ibero-romana de Obulco. Aproximación al estudio comparado de los contextos arqueológicos de su territorio", Anuario Arqueológico de Andalucia, 1988, pp. 238-243.

ARTEAgA, O.; RAMOS, J.; NOCETE, F.; RoOs, A., y LizCANO, R., en prensa: "Reconstrucción del proceso histórico en el territorio de la ciudad ibero-romana de Obulco (Porcuna, Jaén)", Anuario Arqueológico de Andalucia, 1989.

CASARIEGo, A.; CORES, G., y Pliego, F., 1987: Catálogo de plomos monetiformes de la Hispania Antigua, Madrid.

CORBIER, M., 1980: "Salaires et salariat sous le Haut-Empire", Les "Devaluations" à Rome, Roma, vol. 2, pp. 61-101.

CRAWFORD, M. H., 1974: Roman Republican coinage, Cambridge.

GARClA-Bellido, M.a P., 1982: Las monedas de Cástulo en escritura indígena. Historia numismática de una ciudad minera, Barcelona.

- 1985: "The half-victoriatus from the Mogente hoard", Acta Numismática, 15, pp. 65-72.

- 1986: "Nuevos documentos sobre minería y agricultura romanas en Hispania", Archivo Español de Arqueologia, 153-154, pp. 13-46.

- 1990: El Tesoro de Mogente y su entorno monetal, Valencia.

GaRnSEY, P., 1979: "Non-slave Labour in the Roman World", Proceedings of the Sevent International Economic History Congress, Edimburgo, pp. 34-145.

Gonzalbes Cravioto, C., 1987-89: "Nuevas aportaciones al catálogo de los plomos monetiformes hispano-romanos", Numisma, 204-221, pp. 109-123.

González Román, C., y Mangas Manjarrfs, J., 1991: Corpus Inscripciones Latinas de Andalucia. Vol. III: Jaén, Sevilla, Tomo I.

GUADAN, A., 1980: La moneda ibérica. Catálogo de numismática ibérica e ibero-romana, Madrid.

LOMAS SALMONTE, F. J., 1987-1988: "De la condición social de los incolae con especial referencia a Hispania", Habis, 18-19, pp. 383-395.

NAVASCUÉS, J. M.., 1971: Las monedas hispánicas del Museo Arqueológico Nacional de Madrid. II. Ciclo andaluz: grupo bastulo-turdetano. Tesoro de Azaila, Salvacañete y Cerro de la Miranda, Barcelona.

PORTILlo MARTín, R., 1983: Incolae, Córdoba.

RODRf́gueZ NeILA, J. F., 1978: "La situación socio-política de los incolae en el mundo romano", Memorias de Hispania Antigua, II, pp. 147-169.

Rodriguez Oi.iva, P., y Peregrin Pari)(, F., 1980: "Hallazgos numismáticos en Ilurco (Pinos Puente, Granada). Las monedas de cecas hispáni cas", Numisma, 165-167, pp. 187-200.

UNTERMANN, J., 1975: Monumenta Linguarum Hispanicarum, Wiesbaden, 2 vols.

VIVES y ESCUdero, A., 1926: La Moneda Hispánica, Madrid, 2 vols. 